\title{
An Analysis of Chinese Deaf College Students' Career Competitiveness of Educational Fairness
}

\author{
Shao Chen \\ Postgraduate of School of Law and Politics \\ Tianjin University of Technology \\ Tianjin, the People's Republic of China \\ agatha_sunflower@hotmail.com
}

\author{
Tong Xin \\ Professor of Deaf Engineering College \\ Tianjin University of Technology \\ Tianjin, the People's Republic of China \\ tongxin@tjut.edu.cn
}

\begin{abstract}
According to the sixth national population census and the second national sample investigation of the disabled people, the total number of the disabled people was $85,020,000$ in China at the end of 2010. The number of person with hearing disability was $20,540,000$, which constituted $24.16 \%$ of the total number of the disabled people. Nonetheless, at present, the number of Chinese students with hearing disorder accounts for ten thousandth of the number of nationwide. [1]

Obviously, the issues of Chinese deaf college students' education and the problems of unfair employment opportunity still exist, which directly have affected advancement of students' career competitiveness and have caused the whole society wide attention and significance. Therefore, enhancing career competitiveness of deaf college students will be very helpful for the development of special higher education and the realization of educational fairness.
\end{abstract}

Keywords - educational fairness; deaf college students; career competitiveness

\section{INTRODUCTION}

Fairness and justice contain extensive social area. As the basic components and premise of fairness and justice, educational fairness is an important embodiment for harmonious society, and it is an extending of social fair value in educational area. Educational fairness includes equality in educational opportunity, process and quality. Only the above-mentioned fairness are accomplished, will educational result be achieved.[2] The fairness of educational result is reflected through employment rate. With rapid development of Chinese special higher education, the employment situation of disabled college students has been improved. However, the phenomenon of low employment rate desiderates to be improved. It is an important subject to improve deaf college students' employment rate for solving educational fairness problems.

Career competitiveness refers to the capability of being able to choose appropriate profession which fits themselves actively and properly, combining personal characteristics and professional skills with practice in the face of graduation and employment.[3] DeFillippi and Arthur defined career competitiveness as a process for equitable distribution of personal knowledge and skills, which include multiform society, human capital and personal working experience.[4]
The basic structure of deaf college students' career competitiveness is accordance with college students', however, deaf college students have unsubstantial career competitiveness because of communication barriers and vastly unfair education. In addition, according to feedback from employer, hearing disorder impacts work efficiency and needs barrier-free facilities are the issues cause practical difficulties for employment of deaf college students. Consequently, it is a research emphasis to promote deaf college students' career competitiveness for special higher education.

\section{CURRENT EMPloyment Situation of Chinese DEAF COLLEGE STUDENTS}

\section{A. Signing Rate}

Recently, in the context of higher educational popularization and financial crisis, employment situation of college graduates is increasingly grim. Taking the Deaf Engineering College of Tianjin University of Technology as an example, its deaf college students' signing rate is about $30 \%$ lower than average signing rate of the whole school at the same period before students leaving university. [5]

Meanwhile, great majority of deaf college students depend on parents and friends to gain employment support. Only a few students find job by themselves. The independent employment proportion of deaf college students is still remained low even if in areas with private enterprise, overseas-funded enterprise and joint venture, such as Jiangsu, and Shanghai.

\section{B. The Quality of Student Resource}

According to the survey, college students' cultivation quality and structure decide whether they could meet talents demand for society. For this reason, educational quality is an decisive factor that affects graduates employment.[6] Owing to blurry educational goals and insufficient funding, the quality of Chinese deaf higher education needs to be improved.

Nowadays, the training programs of deaf higher education is the revised version consulting undergraduate's plan in every university. In view of unsubstantial academic background and slower speed of information acceptance, there are different emphasis between deaf students and general students in the teaching process. It means that goal 
target of development for deaf students is just to gain the same educational opportunity rather than to train talents. If lacking comprehensive operational ability, deaf students obviously lack competitive ability in talent market.

\section{Income Situation}

Although the country released safeguard policies and related laws and regulations for employment of the disabled, the employers have to provide posts at a certain proportion and select proper position for the disabled. In several categories of the disabled, compared with visual impairment, physical disability and mentally handicap, physical labor function of deaf people is close to healthy people. The income level is not optimistic yet.

Take Shanghai, Hangzhou and Suzhou as example, the average annual income of common people are thirty or forty thousand yuan, but the monthly salary of deaf college students are around one thousand yuan, which is only equal to income level of migrant workers.[7]

\section{III. "BeING SELECTED" of DEAF COLLEGE StUdENTS}

With social progress and establishment of market economic system, higher educational system of the disabled has improved constantly, at the same time, talents should be selected by talent market. Due to most of deaf college students grow up in relatively closed deaf community without actual understanding of society, they lack problemsolving ability and not carefully prepared for integrating into society, so that they are faced with challenge of life and employment. Therefore, the rule of the fittest surviving gives rise to the phenomenon.

At present, our country only has special colleges and universities where deaf college students can be enrolled. There are hardly any special universities or majors for postgraduates in China. However, Gallaudet University. US and Bauman Moscow State Technical University. Russia have complete educational system for deaf college students. As a result, our deaf higher educational system will be demanded perfection urgently. The career prospects are unknown because of few major selection for deaf college students. The range of issues lead to being selected for deaf college students once more.

\section{Social AtTitude Towards Deaf College STUDENTS EMPLOYMENT}

\section{A. The Attitude of Government and Most Enterprise.}

Recently, Chinese government pay a lot of attention on problem of deaf college students' employment and provides great political and financial support. The Ministry of Human Resource, Social Security, Education and China Disabled Persons Federation (CDPF) jointly issued "Notification of Further Improving Employment Work of Deaf Graduates in University" on May 1st, 2009. "Through the process of opening up employment channel, carrying out employment policy and providing employment service, according to the principle of priority, preference and high quality, deaf graduates should be supported preferentially as people with difficulties in finding jobs" was explicitly stipulated.
In the section on "Care and Support for Special Education" from "National Medium and Long-term Educational Reform and Development Program (20102020)" declared that disabled students have to improve the comprehensive quality and strengthen vocational skills.

Most of the welfare enterprises, which are suitable for the deaf, mainly can be divided into two categories, one is government sponsored civil administration welfare enterprise, the other one is private welfare enterprise. Both of them hire deaf college students by minimum standards and provide professional training for improving deaf college students" career competitiveness, which makes positive contribution.

\section{B. The Attitude of Social Groups and a Few Enterprise}

Deaf college students' employment rate is lower than visually and physical impaired students in the job market. Although the job fairs face to students with visual impairment, physical disability and mentally handicapped, some enterprises prefer to recruit the blind or persons with physical disabilities.

In contrast, there are fewer posts setting and career training for dear students. Therefore, enterprises and families have to regard deaf students as equal members of the society and change old concepts, respect them, and think on their side. Meanwhile, they need to abandon discrimination and ideas of excessive protection. The deaf students need to be trained with independent and communicated consciousness in their growing process and let themselves into the society as far as possible.

\section{SugGestion}

\section{A. To Build an Inclusive Education System}

Due to hearing impairment and psychological problems, these students would feel inferior to others and not willing to communicate and cooperate with people. It is obvious that inclusive education is the inevitable trend of deaf higher education. Inclusive education advocates that schools should accept all the students, meet their different needs, encourage deaf students and average activities with normal students in classroom.

On one hand, teachers must grasp special educational and psychological knowledge, develop special educational strategy, take an individual education plan, and stimulate students' potential, making every deaf student to get the best education as far as possible. And to do the real equality of education with providing education for all people without discrimination.

On the other hand, deaf students, who study in inclusive class, just depend on teachers' classroom teaching is not enough. Therefore, extracurricular teaching assistant system is needed to help deaf students to preview and review. According to the survey, students from Deaf Engineering College of Tianjin University of Technology have minored second degree by inclusive education mode as early as 2005 . There are about $10 \%$ deaf students getting double degree every year. This university has added four undergraduate 
majors, two engineering majors and two management majors through the inclusive education mode in 2013.

The move is a major breakthrough for deaf higher education in our country. At present, due to national policy, the present situation in the higher education of the deaf and the conditions of the deaf students' cognition, the higher inclusive education for the deaf in China is still in fledging period. The construction of the deaf college students' inclusive education system greatly promotes the process and realization of educational fairness goal for the disabled in our country.

\section{B. To Strengthen Psychological Education}

Environment affects person's development, especially, the social environment has a subtle effect on the development of people. The environment here not only refers to the external environment, such as society, enterprises, schools and families, also includes the positive and healthy environment inside. Only in positive mental environment, the deaf college students can be willing to accept new knowledge, communicate with people and train skills as far as possible. The deaf college students will face social role transition, process all kinds of problems such as interpersonal relations and employment.

The institutions of higher education should create a good internal and external environment, strengthen psychological health education and employment guidance, carry out psychological counseling and group counseling, hold lectures and discussion of employment, take the initiative to guide the deaf students to realize self-fulfillment and social value, and promote the deaf students' professional selfconfidence and competence. The deaf college students' psychological health education should be included in the higher education training system and run through the whole process of deaf higher education. The sophomore year and junior year are the best period for psychological education and career counseling. For these reasons, the best choice is to combine group counseling with individual counseling.

\section{To Improve the Quality of Talent Cultivation}

To work out a training plan with goal of developing human resources hold a great significance for the development of deaf higher education and the guarantee of education effect.

First of all, institutions of deaf higher education shall be fully considering the physiological characteristics of deaf students, starting from the curriculum, teaching outline, teaching method, and practice, etc. Training plans would be created from multiple views, which are not merely as educational mythologies, but function as professional skills.
Social adaptability and occupational competence of deaf students would be taken seriously to realize education fairness.

Second, extensive majors and curriculum setting need to combine with training programs. Inclusive education is a direction, all colleges and universities could timely communicate with other departments, increase curriculum choice of inclusive education and internship practice, expand deaf students' horizon and enrich their knowledge.

Finally, to establish a deaf higher education teaching staff, which can meet the needs of education, with good quality, reasonable structure. It can fundamentally ensure the quality of teaching and enhance students' comprehensive quality, so as to achieve the ultimate goal of promoting deaf college students' career competitiveness.

Educational fairness is the basis of improving the deaf college students' employment rate, it is also the fundamental guarantee of deaf college students' vocational competitiveness. The development of deaf higher education and the era of inclusive education are bound to accelerate the pace of realization educational fairness's goals.

\section{ACKNOWLEDGMENT}

Fund project-Education Ministry for the Planning of Humanities and Social Sciences,2011 (Item No. 11YJA880096).

\section{REFERENCES}

[1] Li Huomin, A research Overview of Employment Problem for Chinese Deaf College Students [J]. Academic Forum, September 2012 .

[2] Ma Ming, Wu Hongjun, Tan Han. A Study of Higher Education for The Disabled from The Perspective of Educational Fairness[J]. Journal of Higher Education Management, September 2009.

[3] Yao Dan, A Research of Intervening Measure and Effect about Chinese Deaf College Students' Career Competitiveness[D]. Tianjin University of Technology, Tianjin. 2013.

[4] He Ying, A Research of Managers' Career Competitiveness[D], Xi' an University of Technology. 2010.

[5] Yao Dan, A Research of Intervening Measure and Effect about Chinese Deaf College Students' Career Competitiveness[D]. Tianjin University of Technology, Tianjin. 2013.

[6] Yan Jingjing, A Research of Influencing Factor about The Disabled College Students' Employment--Take Three Universities as Example in Shang Hai[D], East China Normal University, Shang Hai. 2008.

[7] Qing Zujie, Zhou Chunmei, The Issues, Influencing Factors and Countermeasure about Deaf College Students' Employment[J], Chinese Journal of Special Education, July 2006. 